\title{
State-Specific Prevalence of Obesity Among Children Aged 2-4 Years Enrolled in the Special Supplemental Nutrition Program for Women, Infants, and Children — United States, 2010-2016
}

\author{
Liping Pan, $\mathrm{MD}^{1}$; Heidi M. Blanck, $\mathrm{PhD}^{1}$; Sohyun Park, $\mathrm{PhD}^{1}$; Deborah A. Galuska, $\mathrm{PhD}^{1}$; David S. Freedman, $\mathrm{PhD}^{1}$; \\ Anna Potter, MPP${ }^{2}$; Ruth Petersen, $\mathrm{MD}^{1}$
}

Obesity negatively affects children's health because of its associations with cardiovascular disease risk factors, type 2 diabetes, asthma, fatty liver disease, victimization stemming from social stigma and bullying, and poor mental health (e.g., anxiety and depression) (1). Children who have overweight or obesity in early childhood are approximately four times as likely to have overweight or obesity in young adulthood as their normal weight peers (2). Obesity prevalence is especially high among children from low-income families (3). In 2010 , the overall upward trend in obesity prevalence turned downward among children aged 2-4 years enrolled in the Special Supplemental Nutrition Program for Women, Infants, and Children (WIC), a program of the U.S. Department of Agriculture (USDA); prevalence decreased significantly in all racial/ethnic groups and in 34 of the 56 WIC state or territory agencies during 2010-2014 (4). A more recent study among young children enrolled in WIC reported that the overall obesity prevalence decreased from $15.9 \%$ in 2010 to $13.9 \%$ in 2016 and statistically significant decreases were observed in all age, sex, and racial/ethnic subgroups (3). However, this study did not provide obesity trends at the state level. In collaboration with USDA, CDC used data from the WIC Participant and Program Characteristics (WIC PC) to update state-specific trends through 2016. During 2010-2016, modest but statistically significant decreases in obesity prevalence among children aged 2-4 years enrolled in WIC occurred in 41 $(73 \%)$ of 56 WIC state or territory agencies. Comprehensive approaches that create positive changes to promote healthy eating and physical activity for young children from all income levels, ${ }^{*}$ strengthen nutrition education and breastfeeding support among young children enrolled in WIC, and encourage redemptions of healthy foods in WIC food packages could help maintain or accelerate these declining trends.

As a federal grant program, WIC is administered by states, territories, and Indian Tribal Organizations to provide supplemental nutritious foods, breastfeeding support, health care referrals, and nutrition education for low-income children aged $<5$ years and pregnant, postpartum, or breastfeeding women. WIC PC is a biennial census in even years of all participants certified to receive WIC benefits. WIC state and territory

\footnotetext{
*https://www.nap.edu/read/13275/chapter/1.
}

agencies extract WIC PC data in April of the reporting year. To be eligible for WIC, participants must live in the states in which they apply, have gross household income $\leq 185 \%$ of the federal poverty guidelines or be eligible for other programs (e.g., Supplemental Nutrition Assistance Program, Medicaid, and Temporary Assistance for Needy Families), and be at nutrition risk. ${ }^{\dagger}$ Children's weight and height are measured by WIC staff members during certification and recertification clinical visits. $\$$

Obesity was defined as a body mass index $\geq 95$ th percentile for age and sex on the 2000 CDC growth charts. 9 To estimate relative change in obesity prevalence during 2010-2016, a log binomial regression analysis was performed for each WIC state or territory agency to obtain the prevalence ratio from 2010 to 2016 adjusted for age, sex, and race/ethnicity, using SAS software (version 9.4; SAS Institute). An obesity trend was considered statistically significant if the two-sided p-value was $<0.05$ in state-level log binomial regression model including all years of data. For absolute change in obesity prevalence, marginal effect was obtained from state-level logistic regression using the Margins package in $\mathrm{R}$ software (version 3.6; R Foundation for Statistical Computing) to show the adjusted prevalence difference from 2010 to 2016.

The final analytic sample included 12,403,629 children aged 2-4 years enrolled in the program from WIC agencies in 50 states, the District of Columbia, and five U.S. territories in 2010, 2012, 2014, and 2016. Among approximately 12.6 million original enrollees, a total of 171,272 (1.4\%) children whose age, sex, weight, height, or body mass index were missing and 44,578 (0.4\%) children whose anthropometric data were biologically implausible were excluded; biologically implausible z scores were defined as height for age $<-5.0$ or $>4.0$, weight for age $<-5.0$ or $>8.0$, and body mass index for age $<-4.0$ or $>8.0$. $^{* *}$

In 2010, crude obesity prevalence ranged from $9.6 \%(95 \%$ confidence interval $[\mathrm{CI}]=9.3 \%-9.8 \%$ ) in Colorado to $21.5 \%$ $(95 \%$ CI $=21.2 \%-21.9 \%)$ in Virginia (Table). Obesity

\footnotetext{
$\dagger$ https://www.fns.usda.gov/wic/wic-eligibility-requirements.

$\$$ https://wicworks.fns.usda.gov/wicworks/Sharing_Center/PA/Anthro/lib/pdf/ Anthropometric_Training_Manual.pdf.

I https://www.cdc.gov/growthcharts/cdc_charts.htm.

** https://www.cdc.gov/nccdphp/dnpao/growthcharts/resources/sas.htm.
} 
TABLE. Prevalence of obesity among children aged 2-4 years enrolled in the Special Supplemental Nutrition Program for Women, Infants, and Children (WIC), by WIC state or territory agency — United States, 2010-2016

\begin{tabular}{|c|c|c|c|c|c|c|}
\hline \multirow[b]{2}{*}{ State } & \multicolumn{2}{|r|}{2010} & \multicolumn{2}{|r|}{2016} & \multicolumn{2}{|c|}{2016 versus 2010} \\
\hline & No. & $\begin{array}{c}\text { Crude prevalence } \\
\%(95 \% \mathrm{Cl})\end{array}$ & No. & $\begin{array}{c}\text { Crude prevalence } \\
\%(95 \% \mathrm{Cl})\end{array}$ & $\begin{array}{l}\text { Adjusted prevalence } \\
\text { ratio* }(95 \% \mathrm{Cl})\end{array}$ & $\begin{array}{l}\text { Adjusted prevalence } \\
\text { difference }{ }^{\dagger} \%(95 \% \mathrm{Cl})\end{array}$ \\
\hline Alabama $a^{\S, 9}$ & 45,743 & 15.8 (15.5 to 16.2$)$ & 42,671 & 16.3 (15.9 to 16.6$)$ & 1.03 (1.00 to 1.06$)$ & 0.5 (0.0 to 1.0$)$ \\
\hline Alaska** & 10,108 & 21.2 (20.4 to 22.0$)$ & 5,983 & 19.8 (18.8 to 20.8 ) & 0.92 (0.86 to 0.97$)$ & $-1.6(-2.8$ to -0.3$)$ \\
\hline Arizona** & 72,933 & 15.0 (14.8 to 15.3$)$ & 58,054 & 12.1 (11.8 to 12.3$)$ & 0.81 (0.79 to 0.84$)$ & $-2.7(-3.1$ to -2.4$)$ \\
\hline Arkansas** & 31,245 & $14.8(14.4$ to 15.2$)$ & 23,647 & 13.3 (12.8 to 13.7$)$ & 0.90 (0.87 to 0.94$)$ & $-1.4(-2.0$ to -0.8$)$ \\
\hline California** & 583,008 & 18.4 (18.3 to 18.5$)$ & 495,095 & 15.5 (15.4 to 15.6$)$ & 0.86 (0.86 to 0.87$)$ & $-2.5(-2.6$ to -2.3$)$ \\
\hline Colorado** & 39,612 & 9.6 (9.3 to 9.8$)$ & 31,307 & 8.1 (7.8 to 8.4$)$ & 0.85 (0.81 to 0.90$)$ & $-1.4(-1.8$ to -1.0$)$ \\
\hline Connecticut ${ }^{* *}$ & 22,988 & 17.1 (16.6 to 17.6$)$ & 18,748 & 14.4 (13.9 to 14.9 ) & 0.87 (0.83 to 0.91$)$ & $-2.2(-2.9$ to -1.5$)$ \\
\hline Delaware & 7,650 & 18.4 (17.5 to 19.2$)$ & 6,906 & $16.2(15.3$ to 17.0$)$ & 0.93 (0.87 to 1.00$)$ & $-1.1(-2.3$ to 0.2$)$ \\
\hline District of Columbia** & 5,182 & $14.4(13.5$ to 15.4$)$ & 5,181 & 11.4 (10.5 to 12.3$)$ & 0.83 (0.75 to 0.91$)$ & $-2.4(-3.7$ to -1.1$)$ \\
\hline Florida** & 194,924 & 14.6 (14.4 to 14.7$)$ & 193,749 & 12.7 (12.6 to 12.9$)$ & 0.87 (0.86 to 0.89 ) & $-1.8(-2.0$ to -1.6$)$ \\
\hline Georgia** & 104,959 & 14.4 (14.2 to 14.6$)$ & 78,023 & 12.5 (12.3 to 12.8$)$ & 0.88 (0.86 to 0.90$)$ & $-1.8(-2.1$ to -1.4$)$ \\
\hline Hawaii & 14,504 & 9.7 (9.3 to 10.2$)$ & 11,589 & 9.6 (9.1 to 10.1$)$ & 0.98 (0.91 to 1.06$)$ & $-0.2(-0.9$ to 0.6$)$ \\
\hline Idaho** & 18,704 & $11.9(11.5$ to 12.4$)$ & 14,521 & 11.3 (10.8 to 11.8 ) & 0.95 (0.89 to 1.00$)$ & $-0.6(-1.3$ to 0.1$)$ \\
\hline Illinois** & 108,762 & 15.7 (15.5 to 15.9$)$ & 79,949 & 14.8 (14.6 to 15.0$)$ & 0.98 (0.96 to 1.00$)$ & $-0.3(-0.6$ to 0.1$)$ \\
\hline Indiana** & 63,220 & 15.1 (14.8 to 15.4$)$ & 55,955 & 13.0 (12.7 to 13.2$)$ & 0.91 (0.88 to 0.93 ) & $-1.4(-1.8$ to -1.0$)$ \\
\hline lowa & 29,481 & 15.6 (15.2 to 16.0$)$ & 24,427 & 15.2 (14.8 to 15.7$)$ & 1.00 (0.96 to 1.04$)$ & $0.0(-0.6$ to 0.6$)$ \\
\hline Kansas** & 30,458 & $13.7(13.4$ to 14.1$)$ & 24,306 & 12.5 (12.1 to 12.9$)$ & 0.91 (0.87 to 0.95$)$ & $-1.3(-1.8$ to -0.7$)$ \\
\hline Kentucky** & 45,761 & 18.2 (17.9 to 18.6$)$ & 38,361 & 15.9 (15.6 to 16.3$)$ & 0.88 (0.85 to 0.91$)$ & $-2.2(-2.7$ to -1.7$)$ \\
\hline Louisiana** & 48,145 & 13.8 (13.5 to 14.1$)$ & 37,527 & 13.2 (12.9 to 13.6$)$ & 0.94 (0.91 to 0.98$)$ & $-0.8(-1.2$ to -0.3$)$ \\
\hline Maine ${ }^{* *}$ & 10,410 & $15.2(14.6$ to 15.9$)$ & 8,233 & 13.9 (13.2 to 14.7$)$ & 0.92 (0.85 to 0.98$)$ & $-1.3(-2.3$ to -0.2$)$ \\
\hline Maryland ${ }^{* *}$ & 51,280 & 17.1 (16.8 to 17.4$)$ & 50,469 & 15.6 (15.3 to 16.0$)$ & 0.92 (0.90 to 0.95$)$ & $-1.3(-1.8$ to -0.9$)$ \\
\hline Massachusetts** & 49,178 & 17.1 (16.8 to 17.5$)$ & 41,740 & 16.4 (16.0 to 16.7$)$ & 0.94 (0.91 to 0.96$)$ & $-1.0(-1.5$ to -0.6$)$ \\
\hline Michigan** & 85,293 & 14.4 (14.2 to 14.6$)$ & 84,387 & 13.3 (13.1 to 13.5$)$ & 0.95 (0.93 to 0.97$)$ & $-0.7(-1.0$ to -0.3$)$ \\
\hline Minnesota** & 57,529 & $12.7(12.4$ to 13.0$)$ & 47,219 & 12.2 (11.9 to 12.5$)$ & 0.95 (0.92 to 0.98$)$ & $-0.6(-1.0$ to -0.2$)$ \\
\hline Mississippi** & 36,519 & 14.9 (14.6 to 15.3$)$ & 28,493 & 14.4 (14.0 to 14.8$)$ & 0.96 (0.92 to 0.99$)$ & $-0.6(-1.2$ to -0.1$)$ \\
\hline Missouri** & 50,575 & $14.4(14.1$ to 14.8$)$ & 43,404 & 12.3 (12.0 to 12.6$)$ & 0.86 (0.83 to 0.88$)$ & $-2.1(-2.5$ to -1.6$)$ \\
\hline Montana & 7,194 & 13.4 (12.6 to 14.2$)$ & 6,647 & 12.1 (11.3 to 12.8$)$ & 0.89 (0.82 to 0.97$)$ & $-1.5(-2.6$ to -0.4$)$ \\
\hline Nebraska & 15,622 & 14.4 (13.8 to 14.9$)$ & 13,807 & 15.2 (14.6 to 15.7$)$ & 1.05 (1.00 to 1.11$)$ & 0.8 (0.0 to 1.6$)$ \\
\hline Nevada** & 25,855 & 15.0 (14.6 to 15.5$)$ & 24,493 & $11.6(11.2$ to 12.0$)$ & 0.80 (0.77 to 0.84$)$ & $-2.9(-3.5$ to -2.3$)$ \\
\hline New Hampshire & 7,263 & $15.0(14.1$ to 15.8$)$ & 6,042 & 15.8 (14.9 to 16.7$)$ & 1.05 (0.97 to 1.14 ) & 0.8 ( -0.5 to 2.0$)$ \\
\hline New Jersey** & 59,000 & 18.9 (18.6 to 19.2 ) & 53,917 & 15.0 (14.7 to 15.3$)$ & 0.80 (0.78 to 0.82$)$ & $-3.9(-4.3$ to -3.4$)$ \\
\hline New Mexico** & 21,968 & 15.7 (15.2 to 16.1$)$ & 18,619 & 12.1 (11.6 to 12.5$)$ & 0.77 (0.73 to 0.81$)$ & $-3.7(-4.4$ to -3.0$)$ \\
\hline New York ${ }^{* *}$ & 186,760 & 16.1 (16.0 to 16.3 ) & 182,401 & 13.7 (13.6 to 13.9$)$ & 0.88 (0.87 to 0.89 ) & $-1.9(-2.1$ to -1.7$)$ \\
\hline North Carolina ${ }^{\S, 9}$ & 89,798 & 13.9 (13.6 to 14.1$)$ & 97,286 & 14.2 (14.0 to 14.5$)$ & 1.04 (1.02 to 1.06$)$ & $0.6(0.3$ to 0.9$)$ \\
\hline North Dakota & 5,484 & 14.5 (13.5 to 15.4$)$ & 4,723 & $14.3(13.3$ to 15.3$)$ & 0.99 (0.90 to 1.09$)$ & $-0.1(-1.4$ to 1.3$)$ \\
\hline Ohio & 102,803 & 12.6 (12.4 to 12.8$)$ & 74,753 & 12.4 (12.2 to 12.6$)$ & 0.98 (0.96 to 1.01$)$ & $-0.2(-0.5$ to 0.1$)$ \\
\hline Oklahoma** & 37,849 & 15.4 (15.1 to 15.8$)$ & 34,486 & 13.1 (12.8 to 13.5$)$ & 0.85 (0.82 to 0.88$)$ & $-2.4(-2.9$ to -1.8$)$ \\
\hline Oregon** & 43,209 & 15.8 (15.5 to 16.2$)$ & 34,485 & $14.7(14.4$ to 15.1$)$ & 0.94 (0.91 to 0.97$)$ & $-1.0(-1.5$ to -0.5$)$ \\
\hline Pennsylvania** & 96,762 & $12.8(12.6$ to 13.1$)$ & 80,202 & $12.2(12.0$ to 12.4$)$ & 0.96 (0.94 to 0.98$)$ & $-0.5(-0.8$ to -0.2$)$ \\
\hline Rhode Island** & 10,783 & $16.4(15.7$ to 17.1$)$ & 6,984 & 15.4 (14.5 to 16.2$)$ & 0.93 (0.86 to 0.99$)$ & $-1.2(-2.3$ to -0.1$)$ \\
\hline South Carolina** & 39,785 & 13.3 (13.0 to 13.7$)$ & 32,399 & 11.4 (11.1 to 11.8$)$ & 0.89 (0.85 to 0.92$)$ & $-1.5(-2.0$ to -1.0$)$ \\
\hline South Dakota & 7,884 & 17.3 (16.5 to 18.1$)$ & 6,771 & 17.1 (16.2 to 18.0$)$ & 0.95 (0.88 to 1.02$)$ & $-0.8(-2.1$ to 0.4$)$ \\
\hline Tennessee ${ }^{* *}$ & 57,153 & $16.0(15.7$ to 16.3$)$ & 51,157 & 14.6 (14.3 to 14.9$)$ & 0.92 (0.89 to 0.94$)$ & $-1.3(-1.8$ to -0.9$)$ \\
\hline Texas** & 361,823 & 16.9 (16.8 to 17.0$)$ & 268,787 & 14.6 (14.4 to 14.7$)$ & 0.89 (0.88 to 0.90$)$ & $-1.9(-2.0$ to -1.7$)$ \\
\hline Utah** & 26,045 & 12.5 (12.1 to 12.9$)$ & 21,599 & 7.9 (7.6 to 8.3$)$ & 0.64 (0.60 to 0.67 ) & $-4.6(-5.1$ to -4.0$)$ \\
\hline Vermont & 6,964 & $13.8(13.0$ to 14.7$)$ & 5,254 & $14.5(13.5$ to 15.4$)$ & 1.04 (0.95 to 1.13$)$ & $0.6(-0.7$ to 1.8$)$ \\
\hline Virginia ${ }^{9, * *}$ & 48,920 & 21.5 (21.2 to 21.9$)$ & 47,376 & 15.3 (14.9 to 15.6$)$ & 0.73 (0.71 to 0.75$)$ & $-5.8(-6.3$ to -5.3$)$ \\
\hline Washington** & 78,336 & 14.9 (14.6 to 15.1$)$ & 69,870 & 13.3 (13.0 to 13.5$)$ & 0.89 (0.87 to 0.91$)$ & $-1.6(-2.0$ to -1.3$)$ \\
\hline West Virginia ${ }^{\S, \mathbb{q}}$ & 17,669 & 14.4 (13.9 to 14.9$)$ & 14,222 & 16.6 (16.0 to 17.2 ) & 1.15 (1.09 to 1.21$)$ & 2.2 (1.4 to 3.0$)$ \\
\hline Wisconsin** & 48,511 & 15.2 (14.9 to 15.5$)$ & 37,116 & 14.3 (14.0 to 14.7$)$ & 0.94 (0.91 to 0.97 ) & $-0.9(-1.4$ to -0.4$)$ \\
\hline Wyoming** & 4,413 & 11.8 (10.9 to 12.8 ) & 3,458 & 9.1 (8.1 to 10.1) & 0.76 (0.67 to 0.87$)$ & $-2.8(-4.2$ to -1.5$)$ \\
\hline \multicolumn{7}{|l|}{ Territory } \\
\hline American Samoa & 3,221 & $14.6(13.4$ to 15.8$)$ & 2,824 & $13.7(12.4$ to 15.0$)$ & 0.94 (0.83 to 1.06$)$ & $-0.9(-2.7$ to 0.9$)$ \\
\hline Guam** & 3,248 & $11.4(10.3$ to 12.5$)$ & 2,710 & 8.3 (7.3 to 9.4$)$ & 0.73 (0.62 to 0.85$)$ & $-3.1(-4.6$ to -1.6$)$ \\
\hline Northern Mariana Islands** & 2,157 & 14.1 (12.6 to 15.6$)$ & 1,418 & 7.8 (6.4 to 9.2$)$ & 0.55 (0.45 to 0.68$)$ & $-6.4(-8.4$ to -4.4$)$ \\
\hline Puerto Rico** & 70,699 & 20.3 (20.0 to 20.6 ) & 63,251 & 12.0 (11.8 to 12.3$)$ & 0.60 (0.58 to 0.61$)$ & $-8.2(-8.6$ to -7.8$)$ \\
\hline U.S. Virgin Islands & 2,093 & 12.4 (11.0 to 13.8$)$ & 1,593 & 13.1 (11.5 to 14.8$)$ & 1.07 (0.90 to 1.26$)$ & $0.8(-1.4$ to 3.0$)$ \\
\hline
\end{tabular}

Abbreviation: $\mathrm{Cl}$ = confidence interval.

* Obtained from log binomial regression model adjusted for age in month, sex, and race/ethnicity.

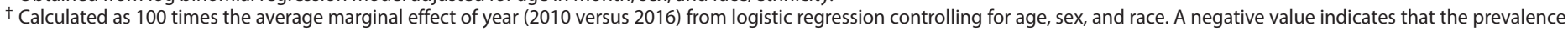
decreased.

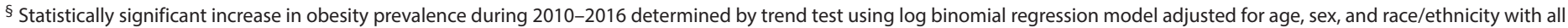
years of data included.

9 Change in the data reporting system in 2016 might affect obesity prevalence.

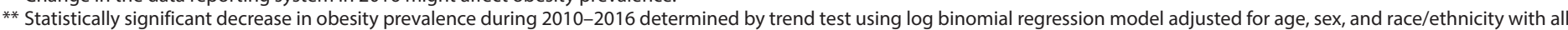
years of data included. 
prevalence was $\geq 20 \%$ among children aged $2-4$ years in three state or territory agencies (Alaska, Puerto Rico, and Virginia) and was $<10 \%$ in only two WIC state agencies (Colorado and Hawaii). In 2016, crude obesity prevalences ranged from 7.8\% $(95 \% \mathrm{CI}=6.4 \%-9.2 \%)$ in the Northern Mariana Islands to $19.8 \%$ (95\% CI $=18.8 \%-19.8 \%)$ in Alaska. Crude obesity prevalence among children aged $2-4$ years was $<20 \%$ in any state or territory and was $<10 \%$ in six WIC state or territory agencies (Colorado, Guam, Hawaii, Northern Mariana Islands, Utah, and Wyoming).

During 2010-2016, statistically significant decreases in obesity prevalence occurred in 41 of 56 WIC state or territory agencies $(\mathrm{p}<0.05$ for trend test) across all years (Table) (Figure). Adjusted obesity prevalences decreased by $>3$ percentage points in seven WIC state or territory agencies (Guam, New Jersey, New Mexico, Northern Mariana Islands, Puerto Rico, Utah, and Virginia); the largest significant decrease was in Puerto Rico, where adjusted obesity prevalence among WIC beneficiaries aged 2-4 years decreased by 8.2 percentage points from 2010 to 2016. Only three WIC state agencies reported significant increases in obesity prevalence across all years; adjusted obesity prevalence increased by 0.5 percentage points in Alabama, 0.6 percentage points in North Carolina, and 2.2 percentage points in West Virginia (Table).

\section{Discussion}

These findings indicate statistically significant decreases in obesity prevalence during 2010-2016 among children aged 2-4 years enrolled in WIC in $41(73 \%)$ of 56 WIC state or territory agencies. A previous study using these data reported that children aged $2-4$ years in 34 (61\%) of 56 WIC state or territory agencies experienced decreases in obesity prevalence during 2010-2014 (4). The present study found that obesity prevalence among children in this age group continued to decrease through 2016 in 33 of the 34 WIC state or territory agencies, with previous significant decreases and identified decreases during 2010-2016 in eight additional WIC agencies having no significant changes during 2010-2014. Although decreases in obesity prevalence in the present study were small, the trends in obesity prevalence among young WIC beneficiaries overall (3) and in the majority of states and territories were in contrast to the national trend, which was that obesity prevalence decreased for children aged 2-5 years from all income levels from $10.1 \%$ in $2007-2008$ to $8.4 \%$ in 2011-2012 and then increased to $13.9 \%$ in 2015-2016 (5). Thus, even these small decreases indicate progress for this vulnerable WIC population.

The WIC program reaches low-income infants and children during the critical period of child growth. One factor that might have contributed to the observed decreases in obesity
FIGURE. Changes* in obesity prevalence among children aged 2-4 years enrolled in the Special Supplemental Nutrition Program for Women, Infants, and Children (WIC), by WIC state or territory agency — United States, 2010-2016

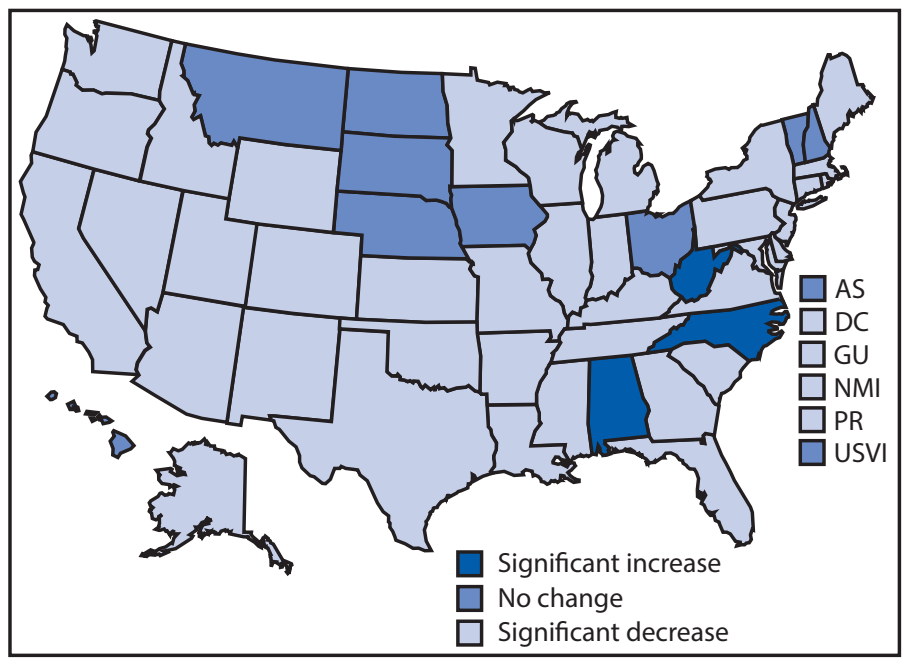

Abbreviations: $\mathrm{AS}=$ American Samoa; $\mathrm{DC}=$ District of Columbia; $\mathrm{GU}=\mathrm{Guam}$; $\mathrm{NMI}=$ Northern Mariana Islands; PR = Puerto Rico; USVI = U.S. Virgin Islands. * Statistically significant changes were determined by trend tests using log binomial regression models adjusted for age, sex, and race/ethnicity with all years of data included.

prevalence in WIC enrollees is the 2009 revisions to the WIC food packages $(6)$, which was carried out to better align with nutrition research, the 2005 Dietary Guidelines for Americans (7), and the infant food and feeding practice guidelines of the American Academy of Pediatrics. ${ }^{\dagger \dagger}$ The revised food packages include a broader range of healthy food options; promote fruit, vegetable, and whole wheat product purchases; support breastfeeding; and give WIC state and territory agencies more flexibility to accommodate cultural food preferences (๑). The WIC package revisions had plausible impact on improving diet quality measured by the Healthy Eating Index-2010 scores among WIC children aged 2-4 years (8). In addition, the availability of healthier foods and beverages in authorized WIC stores has increased. Children enrolled in WIC consumed more fruits, vegetables, and whole grain products and less juice, white bread, and whole milk after the revisions (9) than they did before.

Additional contributors to these decreases in obesity prevalence might include other local, state, and national efforts and programs that affect changes in systems outside of WIC to improve diet quality and physical activity for young children from all income levels, including children enrolled in WIC. For example, CDC distributes funding on a competitive basis to state and local grantees to enable implementation of

\footnotetext{
$\dagger_{\dagger}$ https://www.aap.org/en-us/advocacy-and-policy/aap-health-initiatives/HALFImplementation-Guide/Age-Specific-Content/Pages/Infant-Food-andFeeding.aspx/.
} 


\section{Summary}

What is already known about this topic?

Among children aged 2-4 years enrolled in the Special Supplemental Nutrition Program for Women, Infants, and Children (WIC), obesity prevalence decreased from $15.9 \%$ in 2010 to $13.9 \%$ in 2016 and during 2010-2014, decreased in 34 of the 56 WIC state or territory agencies.

What is added by this report?

During 2010-2016, statistically significant decreases in obesity prevalence among WIC beneficiaries aged 2-4 years occurred in 41 of 56 WIC state or territory agencies; obesity prevalence ranged from $7.8 \%$ to $19.8 \%$.

What are the implications for public health practice?

To accelerate these trends, expanded positive changes in multiple settings to promote healthy eating and physical activity for young children are needed.

childhood obesity prevention strategies through increasing involvement of health care providers, community leaders, and early care and education providers (10). Many of the funding recipients focus on both population-level strategies such as state-level standards that can potentially benefit all children and more directed interventions for populations at the highest risk (10). In addition, CDC provides technical support for states to promote maternity care policies and practices to support breastfeeding in birthing facilities and workplaces. ${ }^{\$ \$}$ CDC also provides support for states and communities to implement nutrition, breastfeeding support, physical activity, and screen time standards in early care and education systems and setting. 99

The findings in this report are subject to at least four limitations. First, approximately 15\% fewer children were enrolled in WIC in 2016, compared with 2010 (3), and characteristics of those enrolled in WIC might have changed over time. Although the trend analyses adjusted for age, sex, and race/ ethnicity, other unmeasured factors might have contributed to the declining trends in obesity. Second, the findings might not apply to all low-income children because children enrolled in WIC might be systematically different from others who are eligible but not enrolled. Third, the study findings cannot be applied to U.S. children from families with other income levels. Finally, certain states changed their data reporting systems in recent years, which might have affected obesity trends. Strengths of this study include the use of a large sample of children enrolled in WIC as derived from census data, allowing for stratification by state or territory and the use of measured weight and height data.

\footnotetext{
\$S https://www.cdc.gov/nccdphp/dnpao/state-local-programs/breastfeeding.html. 99 https://www.cdc.gov/obesity/strategies/childcareece.html.
}

Despite these recent decreases in obesity among children enrolled in WIC, obesity prevalence remained high in most states in 2016. Multiple approaches are needed to address and eliminate childhood obesity. The National Academy of Medicine and other groups have recommended a comprehensive and integrated approach that calls for positive changes in physical activity and food and beverage environments in multiple settings including home, early care and education (e.g., nutrition standards for food served), and community (e.g., neighborhood designs that encourage walking and biking) to promote healthy eating and physical activity for young children. Further implementation of these positive changes across the United States could further the decreases in childhood obesity.

\section{Acknowledgments}

Kelley Scanlon, PhD, U.S. Department of Agriculture; Raymond J. King, PhD, CDC.

Corresponding author: Liping Pan, Lpan@cdc.gov, 770-488-8001.

${ }^{1}$ Division of Nutrition, Physical Activity, and Obesity, National Center for Chronic Disease Prevention and Health Promotion, CDC; ${ }^{2}$ Office of Policy Support, Food and Nutrition Service, U.S. Department of Agriculture, Alexandria, Virginia.

All authors have completed and submitted the International Committee of Medical Journal Editors form for disclosure of potential conflicts of interest. No potential conflicts of interest were disclosed.

\section{References}

1. CDC. Childhood obesity causes \& consequences. Atlanta, GA: US Department of Health and Human Services, CDC; 2019. https://www. cdc.gov/obesity/childhood/causes.html

2. Whitaker RC, WrightJA, Pepe MS, Seidel KD, Dietz WH. Predicting obesity in young adulthood from childhood and parental obesity. N Engl J Med 1997;337:869-73. https://doi.org/10.1056/NEJM199709253371301

3. Pan L, Freedman DS, Park S, Galuska DA, Potter A, Blanck HM. Changes in obesity among U.S. children aged 2 through 4 years enrolled in WIC during 2010-2016. JAMA 2019;321:2364-6. https://doi. org/10.1001/jama.2019.5051

4. Pan L, Freedman DS, Sharma AJ, et al. Trends in obesity among participants aged 2-4 years in the Special Supplemental Nutrition Program for Women, Infants, and Children-United States, 2000-2014. MMWR Morb Mortal Wkly Rep 2016;65:1256-60. https://doi. org/10.15585/mmwr.mm6545a2

5. Hales CM, Fryar CD, Carroll MD, Freedman DS, Ogden CL. Trends in obesity and severe obesity prevalence in US youth and adults by sex and age, 2007-2008 to 2015-2016. JAMA 2018;319:1723-5. https:// doi.org/10.1001/jama.2018.3060

6. US Department of Agriculture. Final rule: revisions in the WIC food packages. Washington, DC: US Department of Agriculture; 2014. https://www.fns.usda.gov/wic/fr-030414

7. US Department of Agriculture; US Department of Health and Human Services. Dietary guidelines for Americans. Washington, DC: US Government Printing Office; 2005. https://health.gov/dietaryguidelines/ dga2005/document/default.htm

8. Tester JM, Leung CW, Crawford PB. Revised WIC food package and children's diet quality. Pediatrics 2016;137:e20153557. https://doi. org/10.1542/peds.2015-3557 
9. Schultz DJ, Byker Shanks C, Houghtaling B. The impact of the 2009 Special Supplemental Nutrition Program for Women, Infants, and Children food package revisions on participants: a systematic review. J Acad Nutr Diet 2015;115:1832-46. https://doi.org/10.1016/j. jand.2015.06.381
10. Petersen R, Pan L, Blanck HM. Racial and ethnic disparities in adult obesity in the United States: CDC's tracking to inform state and local action. Prev Chronic Dis 2019;16:E46. https://doi.org/10.5888/ $\operatorname{pcd} 16.180579$ 